\title{
Polyglutamation of Methotrexate Is Methotrexate a Prodrug?
}

\author{
Bruce A. Chabner, Carmen J. Allegra, Gregory A. Curt, Neil J. Clendeninn, Jacob Baram, Shoichi Koizumi, \\ James C. Drake, and Jacques Jolivet \\ Clinical Pharmacology Branch, Division of Cancer Treatment, National Cancer Institute, Bethesda, Maryland 20205
}

\section{Introduction}

The biochemical pharmacology of anticancer drugs such as methotrexate (MTX) ${ }^{1}$ holds fascination for researchers for many reasons. The foremost reason is the desire to understand how drugs interact with physiologic processes and produce selective destruction of tumor cells; such studies directly address the question of whether there are exploitable differences between normal and malignant cells. While the successes of cancer chemotherapy indicate that such differences do exist, these differences have been hard to define in biochemical terms; thus, the quest continues for a more precise understanding of how drugs work.

A second reason for the intense concern with mechanisms of drug action stems from the insights such work provide regarding normal biological processes. For example, the first descriptions of gene amplification in mammalian cells (1) and the recognition of this phenomenon as a response to inhibitors of DNA synthesis (2) resulted from the work of Schimke and colleagues with drug-resistant tumor cells. Cancer pharmacology has been equally instrumental in elucidating the processes of active transport across cell membranes (MTX) (3), the regulation of nucleotide synthesis (5-fluorouracil and cytosine arabinoside) (4), and DNA repair (radiation and alkylating agents) (5). Thus, investigations of drug action have relevance not only because they enrich our understanding of the mechanisms of cytotoxicity, but also because they lead to a greater understanding of normal cell function.

However, the most immediate reason for studying mechanisms of drug action is the practical benefit of such knowledge for improving therapy. A number of practical applications flow from the understanding of how drugs work, how they are activated or degraded by normal and malignant cells, and what targets they attack. These applications include the prediction of response, the design of better agents that can facilitate response

Address correspondence and reprint requests to Dr. Chabner, Division of Cancer Treatment, Building 31, Room 3A52, National Cancer Institute, Bethesda, MD 20205.

Received for publication 25 April 1985.

1. Abbreviations used in this paper: AICAR T'ase, 5-aminoimidazole carboxamide ribotide transformylase; DHFR, dihydrofolate reductase; $\mathrm{FH}_{2}$, dihydrofolate; $\mathrm{FH}_{4}$, tetrahydrofolate; GAR T'ase, glycinamide ribonucleotide transformylase; MTX, methotrexate; MTXPG, methotrexate polyglutamate; TS, thymidylate synthase.

The Journal of Clinical Investigation, Inc.

Volume 76, September 1985, 907-912 or circumvent mechanisms of resistance, and the rational use of drugs in combination therapies.

MTX, in addition to being one of the most widely used of the anticancer drugs, has been the object of intensive study for all of the above reasons. The fascination with this drug initially related to the simplicity and specificity of its action. It belongs to a highly select class of drugs that are tight-binding enzyme inhibitors. Numerous examples of such antimetabolites are known today, but at the time of its synthesis, 35 years ago, it was a unique compound. Its target was identified as dihydrofolate reductase (DHFR) (Fig. 1), the enzyme required for reduction of dihydrofolate $\left(\mathrm{FH}_{2}\right)$ to tetrahydrolate $\left(\mathrm{FH}_{4}\right) . \mathrm{FH}_{4}$ is the precursor of the active folate cofactor forms required for synthesis of thymidylate, purines, methionine, and serine. Cells exposed to MTX were presumed to die of depletion of reduced folates.

In the past five years, evidence has grown that this picture of MTX action is incomplete. It has been known for many years that physiologic folates are converted to polyglutamyl forms intracellularly in the liver, erythrocytes, and various tissues. These polyglutamates are not only storage forms, which, in contrast to the monoglutamated folates, are not readily transported across the cell membrane, but also have markedly increased affinity for certain folate-dependent enzymes, such as thymidylate synthase (TS), 5-aminoimidazole carboxamide ribotide transformylase (AICAR T'ase), and the triple complex of enzymes that interconvert various forms of reduced folate. The same process of polyglutamation was then found to occur for the folate analog, MTX, and to have important consequences for its actions. First erythrocytes (6) and then human liver (7) were shown to convert MTX to polyglutamate forms (Fig. 2) through the addition of glutamyl groups in an unusual gamma-peptide linkage. The same conversion was then observed in murine (8) and human tumor cells (9) in culture. As a result of these observations, the consequences of polyglutamate formation are only now being appreciated.

The enzyme responsible for this reaction, folylpolyglutamyl synthetase, catalyzes the addition of glutamate groups in gammalinkage to the end carboxyl group of the neighboring folyl glutamate, using ATP as its energy source. While bacterial folylpolyglutamyl synthetase has been purified to homogeneity (10), the enzyme from mammalian sources, including pig (11), rat (12) and beef (13) liver, has only been partially purified. The reduced folates, particularly 5-methyl- $-\mathrm{FH}_{4}$, are superior to MTX as substrates for the mammalian enzyme, as is the alternate folate analog aminopterin (2,4-diaminopteroyl glutamic acid) (14). Further studies of highly purified preparations of this enzyme are required to understand pertinent aspects of its regulation, its catalytic mechanism, and the structure-activity rela- 


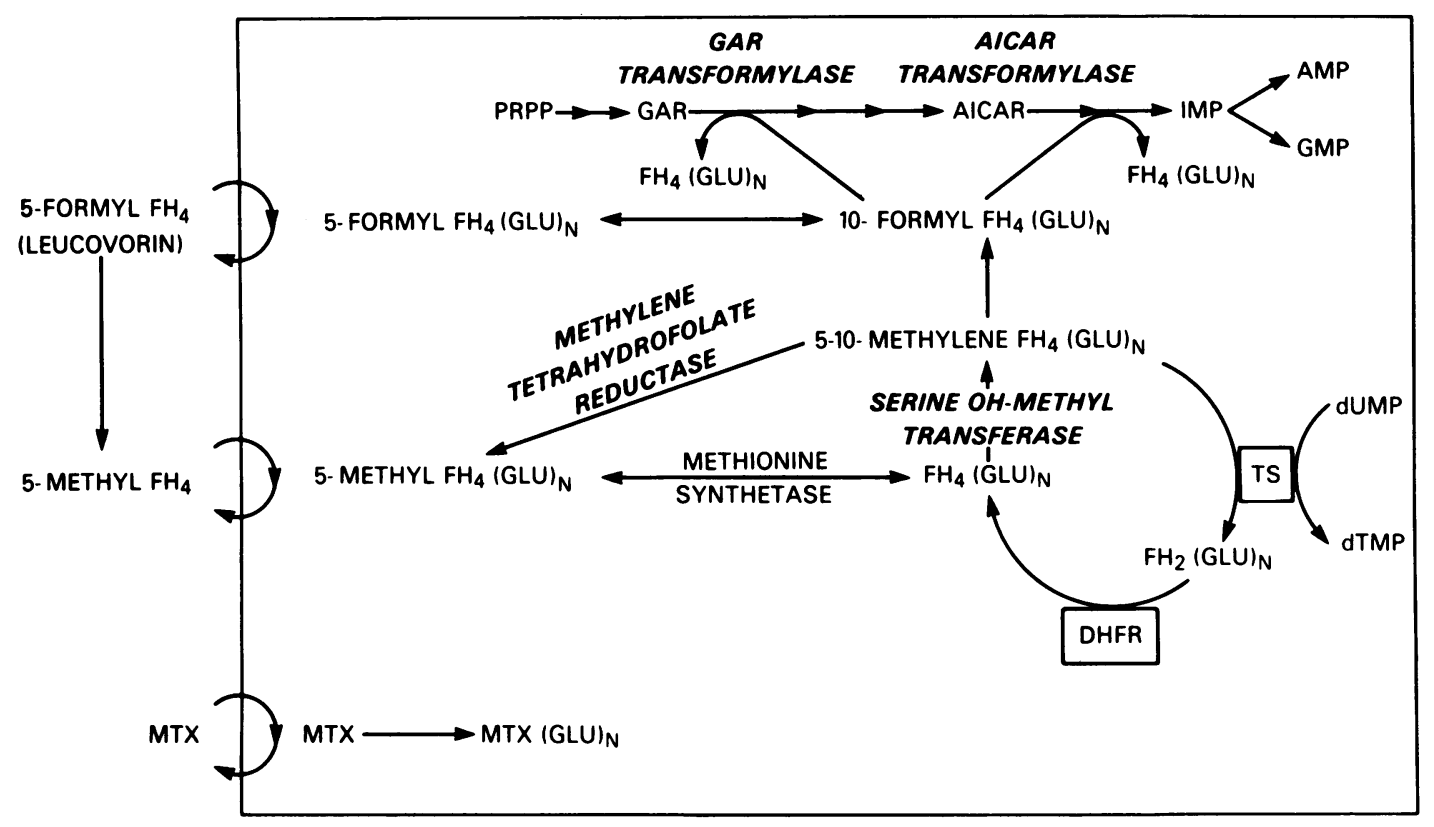

Figure 1. The major enzymatic reactions requiring folates as cosubstrates are illustrated.

tionships of potential substrates and inhibitors; yet, progress in this work has been hampered by the small amount of enzyme activity found in most normal and malignant tissues, the instability of partially purified enzyme, and the low affinity of both the folate and glutamate substrates for this enzyme.

\section{Pharmacologic importance of polyglutamation}

Polyglutamation of MTX, resulting in the addition of one to four new glutamyl groups, takes place in both normal and malignant cells, including liver (7), bone marrow myeloid precursors (15), fibroblasts (16), and erythrocytes (6), as well as human (17) and murine (8) leukemia cells, hepatoma cells (18), human breast cancer cells (9), human small cell carcinoma cells (19), cell lines derived from human head and neck carcinomas (20), and various other human and murine neoplasms. The ability of cells to form polyglutamates of MTX has a number of consequences, all of which enhance the cytotoxic action of MTX. First, the conversion of MTX to a polyglutamate creates a depot form of drug that is not at steady-state with the extracellular drug. Thus cells that accomplish this conversion are able to accumulate vast stores of intracellular drug, in excess of that bound to DHFR; the "free" concentration of polyglutamates thus is many times greater than the unbound intracellular pool of the parent compound (21, 22). In cells incubated with MTX, intracellular drug levels, primarily in the form of polyglutamates, continue to rise for many hours after the establishment of the transport steady-state, which takes place within $30 \mathrm{~min}$ or less, and may reach 30 - to 40 -fold greater concentrations (100-150 $\mathrm{nmol} / \mathrm{mg}$ cellular protein) than the simultaneous concentration of free parent drug (3-10 nmol/ $\mathrm{mg}$ cellular protein). As has been amply demonstrated by the

A

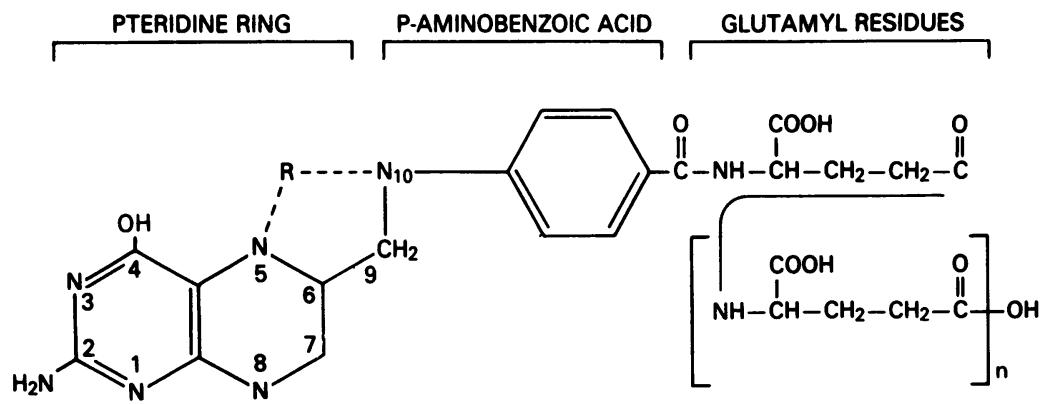

B

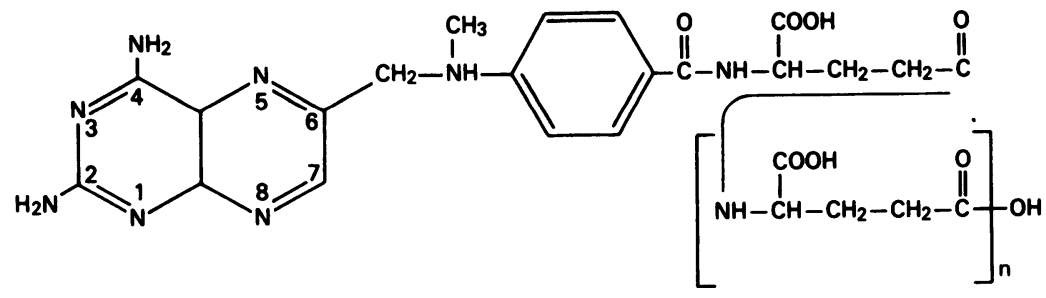

Figure 2. The structures for tetrahydrofolic acid$\mathrm{Glu}_{\mathrm{n}}$ and MTX-Glu $\mathrm{u}_{\mathrm{n}}$ are represented in $(A)$ and $(B)$, respectively. 
work of Goldman and others (23), the presence of excess MTX is important in maintaining a high degree of inhibition of DHFR, since the drug must compete with expanded pools of $\mathrm{FH}_{2}$ for sites on the newly synthesized enzyme or for sites vacated by the intrinsic "off-rate" of inhibitor from enzyme.

Second, the polyglutamates are preferentially retained by cells $(18,22,24)$. When free extracellular drug is removed, the unbound MTX (MTX-Glu $)_{1}$ ) and a significant fraction of MTX$\mathrm{Glu}_{2}$ and $-\mathrm{Glu}_{3}$ are lost from the cell. The retention of higher polyglutamates is a direct function of their chain length. Thus significant fractions of unbound MTX-Glu 4 and most of MTX$\mathrm{Glu}_{5}$ remain in the cells for at least $24 \mathrm{~h}$ after removal of extracellular drug and continue to exert an inhibitory effect on DHFR, DNA synthesis, and cell viability (Fig. 3). There is also evidence that MTX-Glu 5 continues to be synthesized during this period (24) at the expense of the intracellular pools of the shorter length polyglutamates, since the intracellular level of this metabolite continues to rise for $24 \mathrm{~h}$ in the absence of extracellular drug.

The third important feature of methotrexate polyglutamates (MTXPG) is their increased affinity of binding to folate-dependent enzymes. As mentioned previously, DHFR is one of the few such enzymes that does not show a preference for polyglutamated folate substrates. MTX-Glu ${ }_{2}$ did not have greater inhibitory potency than the parent compound in initial studies with crude enzyme preparations (25). However, in studies with intact cells, there appeared to be a slower rate of dissociation of

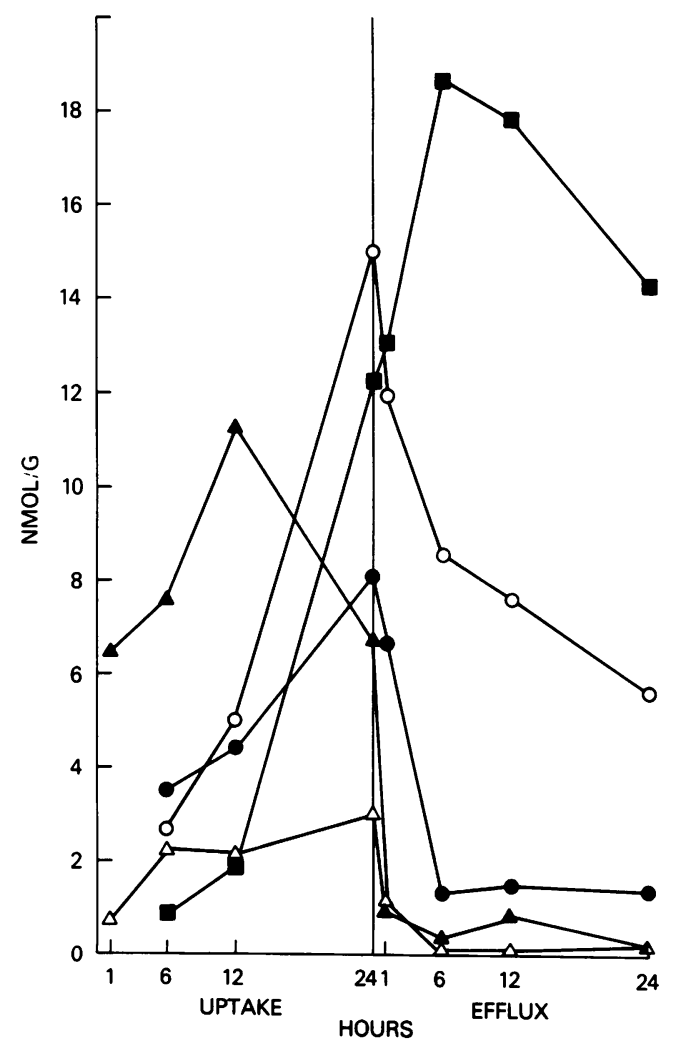

Figure 3. Free MTX and polyglutamates in ZR-75-B cells. MCF-7 breast cancer cells are exposed to $2 \mu \mathrm{M}$ radiolabeled for $24 \mathrm{~h}$, followed by a drug-free period for $24 \mathrm{~h}$. At various time points during and following the drug exposure, MTX and MTXPGs were extracted and quantitated following separation by high pressure liquid chromatogra-

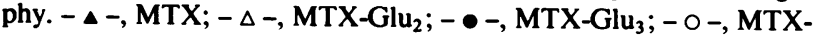
$\mathrm{Glu}_{4} ;-\bullet-$, MTX-Glu . the longer chain length derivatives from DHFR (24) when the radiolabeled polyglutamates were competed off the enzyme by immersing the cells in a vast excess of unlabeled MTX. More recent comparisons of the "on" and "off" rates of binding of

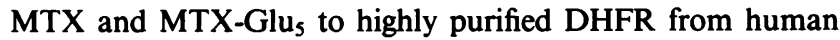
breast cancer cells have confirmed a 40 -fold greater affinity of the latter for DHFR at pH 7.0, primarily due to a faster "on" rate, which isan unexpected finding(Clendeninn, N.J.,J.C.Drake, C. J. Allegra, K. H. Cowan, B. T. Kaufman, S. Evans, and B. A. Chabner, manuscript submitted for publication). These findings help to explain the observation that the polyglutamates gradually replace the parent compound as the primary form of drug bound to DHFR.

Until the discovery of its polyglutamation, MTX was always considered to be a highly specific inhibitor of DHFR (dissociation constant $\left.\left[K_{\mathrm{D}}\right]=7.1 \times 10^{-11} \mathrm{M}\right)$. It does have weak inhibitory effects on TS (inhibition constant $\left[K_{\mathrm{i}}\right]=1.3 \times 10^{-5} \mathrm{M}$ ) but no other significant sites of action. The addition of glutamyl groups to MTX markedly enhances the potency of its inhibition for a number of enzymes (Table I), including TS $(26,27)$ (Fig. 4), AICAR T'ase (28), and glycinamide ribonucleotide transformylase (GAR T'ase) (29). The $K_{\mathrm{i}}$ 's of MTX-Glu ${ }_{5}$ for TS and AICAR T'ase are $\sim 5 \times 10^{-8} \mathrm{M}$, reflecting 250 - and 2,500-fold greater affinity, respectively, for these enzymes as compared with the weak inhibitory effects of the parent compound. While the affinities of MTX-Glu 5 for TS and AICAR T'ase are several orders of magnitude less than its affinity for DHFR, the intracellular concentration of $\mathrm{MTX}-\mathrm{Glu}_{5}$ in drug-sensitive cells is 100 -fold higher than the $K_{\mathrm{i}}$ 's for TS and AICAR T'ase. Thus, it is likely that the metabolite directly inhibits purine and thymidylate synthesis. The inhibitory effects of MTX-Glu 5 on GAR T'ase and methylene- $\mathrm{FH}_{4}$ reductase (29), while greater than those of MTX, are less impressive than the effects on TS and AICAR $T$ 'ase and are of uncertain significance. The polyglutamates have not been tested against methionine synthetase, the enzyme responsible for converting 5-methyl- $\mathrm{FH}_{4}$ to the important metabolic intermediate $\mathrm{FH}_{4}$; this reaction is essential to the utilization of 5-methyl- $\mathrm{FH}_{4}$, the primary circulating form of folate.

Kinetic analysis of the inhibition of TS by MTX and its polyglutamates reveals not only a change in potency of inhibition but also a clear change in the pattern of inhibition from uncompetitive for MTX to noncompetitive inhibition for the polyglutamates (27) (Fig. 4). In kinetic theory, an uncompetitive pattern reflects a requirement of prior binding of substrate or product to the enzyme before the inhibitor will bind, while noncompetitive inhibition requires neither as a precondition. The inhibition of AICAR T'ase by the antifolate and its polyglutamates is straightforwardly competitive but has one unusual and highly important feature (28). The $K_{\mathrm{i}}$ of MTX-Glu $\mathrm{M}_{5}$ in the presence of a monoglutamate substrate, 10 -formyl- $\mathrm{FH}_{4}$, is $6 \times 10^{-8} \mathrm{M}$, but is markedly reduced to $6 \times 10^{-6} \mathrm{M}$ in the presence of a polyglutamated substrate. A mechanistic interpretation of this finding is that the binding of polyglutamated substrate to one of the two catalytic subunits of the enzyme either physically hinders the binding of the inhibitor to the free catalytic subunit or allosterically affects binding to the second catalytic site. As a general principle, the magnitude of the effects of the MTXPGs on these "other" enzymes will depend upon the concentration of folate cofactors in the cell, and in the case of AICAR T'ase, will be markedly affected by the state of polyglutamation of these folates.

What is the relevance of these findings with respect to MTX action? There are two alternative theories to be entertained in 
Table I. Inhibition of Folate-dependent Enzymes by 4-NH $-10-\mathrm{CH}_{3} \mathrm{PteGlu}$ and $-\mathrm{Glu}_{5}$

\begin{tabular}{|c|c|c|c|c|}
\hline \multirow[b]{2}{*}{ Enzyme* } & \multirow[b]{2}{*}{ Folate cofactor } & \multicolumn{2}{|l|}{$K_{\mathrm{i}}(\mu M)$} & \multirow{2}{*}{$\begin{array}{l}K_{i} \text { MTX-Glu } \\
K_{i} \text { MTX-Glu }\end{array}$} \\
\hline & & MTX-Glu & MTX-Glus & \\
\hline \multirow[t]{2}{*}{ TS } & 5-10- $\mathrm{CH}_{2}-\mathrm{H}_{4}$ PteGlu & 13.0 & 0.047 & 277 \\
\hline & $5-10-\mathrm{CH}_{2}-\mathrm{H}_{4} \mathrm{PteGlu}_{5}$ & 14.3 & 0.056 & 255 \\
\hline \multirow[t]{2}{*}{ AICAR T'ase } & 10-formyl-H ${ }_{4}$ PteGlu & 143.9 & 0.057 & 2508 \\
\hline & 10-formyl-H ${ }_{4} \mathrm{PteGlu}_{5}$ & 40.0 & 5.89 & 6.8 \\
\hline GAR T'ase & 10-formyl-H ${ }_{4} \mathrm{PteGlu}$ & 80 & 2.5 & 32 \\
\hline MTR & $5-10-\mathrm{CH}_{2}-\mathrm{H}_{4} \mathrm{PteGlu}$ & 6.4 & 0.15 & 43 \\
\hline SH & $\mathrm{H}_{4}$ PteGlu & No inhibition & No inhibition & 0 \\
\hline
\end{tabular}

* MTR, methylene tetrahydrofolate reductase; SH, serine hydroxymethyl transferase.

explaining the cytotoxicity of MTX. The first, the depletion theory, explains the drug's action on the basis of the blockade of DHFR, with resulting depletion of intracellular reduced folate. The alternative explanation, the competition theory, states that, in addition to depletion of reduced folates, there is direct inhibition of distal steps in the synthesis of nucleotides at the level of TS and AICAR T'ase; this latter inhibition requires compet- itive amounts of reduced folates to reverse the action of MTXPGs at these sites. Which is correct? To be valid, any explanation must account for the observed facts that the drug's cytotoxicity can be prevented either by competitive amounts of reduced folate (leucovorin or 5-methyl- $\mathrm{FH}_{4}$ ) or by thymidine and a purine, such as hypoxanthine. While either theory would explain the reversal by thymidine and a purine, the depletion theory does
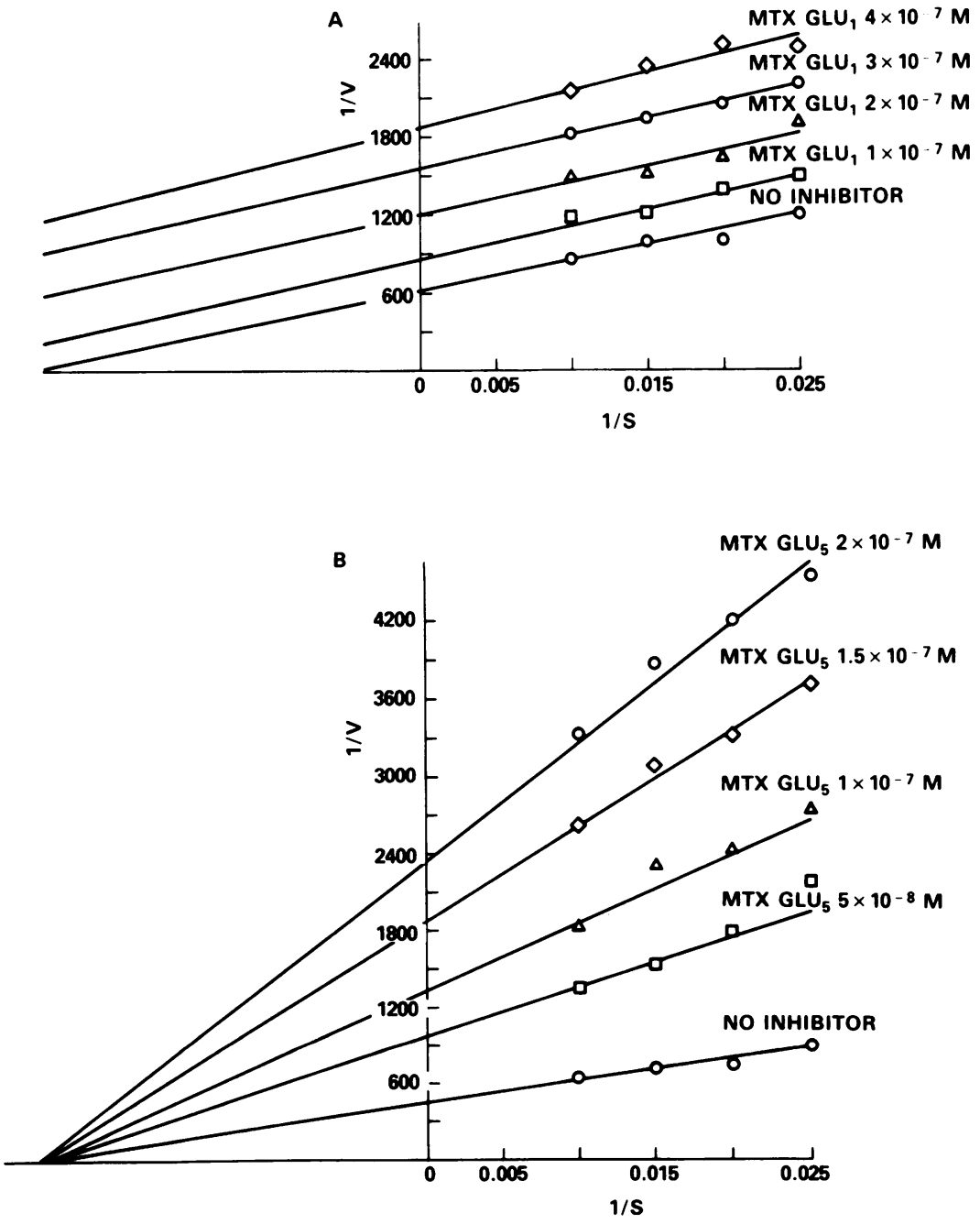

Figure 4. Inhibition of TS by MTX $(A)$ and MTX$\mathrm{Glu}_{5}(B)$. TS was purified from human breast cancer cells and the inhibition kinetics were studied using a tritium-release assay. $\mathrm{V}$, moles of TMP formed per minute $\times 10^{6} ; \mathrm{S}$, concentration of the methylene$\mathrm{FH}_{4}$ cofactor $\times 10^{6}$. 
not explain the requirement for competitive amounts of reduced folate for rescue (30). It is true that MTX and leucovorin compete at the level of transmembrane transport for entry into the cell. However, the requirement for $10^{-4} \mathrm{M}$ leucovorin to rescue $10^{-5}$ M MTX implies that more than a simple repletion of intracellular folates is required for rescue, since the level of intracellular folate would probably be repleted manifold at this concentration of leucovorin. To answer this question definitively, experiments must be performed measuring the effects of MTX on intracellular reduced folates and the relationship of these folate pools to MTXPGs during rescue.

Both the competition and depletion hypotheses of MTX action would ascribe an important role to extracellular circulating folates (primarily 5-methyl- $\mathrm{FH}_{4}$ ) and to the intracellular pool of reduced folates present at the time of drug exposure. There is little information at present as to the absolute levels of intracellular folates and the influence of these folate pools on cytotoxicity. MTX may directly affect the circulating folate levels in addition to its effect on intracellular folates. For example, the MTXPGs are rather potent inhibitors of methylene- $\mathrm{FH}_{4}$ reductase, which converts 5-10-methylene- $\mathrm{FH}_{4}$ to 5-methyl- $\mathrm{FH}_{4}$, the primary circulating form of folate (Table I). MTXPGs could thus inhibit the release of 5-methyl- $\mathrm{FH}_{4}$ from the liver and lower the circulating level of reduced folates that compete with MTX. On the other hand, the repeated administration of leucovorin may increase intracellular levels of reduced folate and produce refractoriness to subsequent doses of MTX. It is clear that knowledge of the intracellular and circulating folate pools is critical to an understanding of MTX action.

In addition to its relevance to the mechanisms of action of MTX, the polyglutamation process appears likely to be an important determinant of tumor sensitivity and the drug's selectivity of action against malignant as compared with normal tissues. With respect to selectivity of action, two normal tissues, gastrointestinal epithelium and bone marrow tissues, are the primary sites of MTX toxicity. In the mouse, DNA synthesis in both of these tissues is potently inhibited during drug exposure but recovers very rapidly as the concentration of MTX in the extracellular space falls below $1 \times 10^{-8} \mathrm{M}$, an indication that neither tissue accumulates long-acting polyglutamates to a significant degree (31). Fabre et al. found little polyglutamate formation in the intestinal mucosa (32) or bone marrow (33) of mice following drug exposure, in contrast to the very obvious formation of polyglutamates in Ehrlich ascites tumor cells. Koizumi et al. (15) purified the myeloid precursor cells from human bone marrow, obtaining a fraction that contained $80 \%$ myeloblasts and promyelocytes, and found diminished capacity to form MTXPGs in comparison with a promyelocytic leukemia cell line (HL-60) and breast cancer cell lines. As expected, the myeloid precursor cells were capable of converting MTX to the entire spectrum of di- to pentaglutamates, but the concentration of these metabolites produced by $10^{-6} \mathrm{M}$ MTX was insufficient to maintain inhibition of DHFR when the free drug was removed. Thus it appears that at least some malignant cell lines have markedly greater capacity to convert MTX to polyglutamates, as compared with normal tissues, and that this capacity is associated with drug sensitivity.

The actual relationship of polyglutamation to drug sensitivity of tumors has been examined only for a very few cell lines. A general statement can be made that the capacity to produce MTXPGs is associated with drug sensitivity in breast cancer cell lines (21), in human small cell carcinoma cell lines (19), and in head and neck carcinoma cell lines (20). In particular, if drug exposure is limited to brief periods ( $24 \mathrm{~h}$ or less), cell lines that do not form polyglutamates are insensitive to the drug since these conditions, which approximate clinical chemotherapy exposure, emphasize the importance of producing a depot form of drug. Continuous exposure to drug negates the importance of polyglutamation. Obviously, any number of factors, including failure to transport MTX and increased levels of DHFR, can indirectly lead to low levels of polyglutamates. Thus, an inability of cells to convert MTX to polyglutamates does not necessarily indicate a lack of the enzyme folylpolyglutamyl synthetase. In fact, there are no well-studied examples of cells in which resistance can be clearly ascribed to a deficiency of this enzyme. Cowan et al. (34) have described a highly resistant human breast cancer cell line that has multiple defects, which include a decreased capacity to transport MTX as well as a decreased ability to form polyglutamates; yet, in this line, the levels of folylpolyglutamyl synthetase are as high as in the parent-sensitive line. Whether drug resistance in human tumors is associated with defective polyglutamation remains to be established.

In conclusion, the discovery of the polyglutamation process has complicated, but enriched, our understanding of the manner in which antimetabolites selectively kill tumor cells. It has focused our attention on the enzyme folylpolyglutamyl synthetase and has heightened the importance of gaining a clearer understanding of normal folate physiology and the effects of drug treatment on circulating and intracellular folates. With this new appreciation for the metabolic pathways of intracellular folates, it will be possible to design more effective treatment regimens and better antifolate agents.

\section{References}

1. Schimke, R. T. 1984. Cell. 37:705-713.

2. Brown, P. C., T. D. Tisty, and R. T. Schimke. 1983. Mol. Cell Biol. 3:1097-1107.

3. Goldman, I. D., N. S. Lichtenstein, and V. T. Oliverio. 1968. J. Biol. Chem. 243:5007-5017.

4. de Saint Vincent, B. R., and G. Buttin. 1980. Biochim. Biophys. Acta. 610:352-359.

5. Erickson, L. C., G. Laurent, N. A. Sharkey, and K. W. Kohn. 1980. Nature (Lond.). 288:727-729.

6. Baugh, C. M., C. L. Krumdieck, and M. G. Nair. 1973. Biochem. Biophys. Res. Commun. 52:27-34.

7. Jacobs, S. A., C. J. Derr, and D. G. Johns. 1977. Biochem. Pharmacol. 26:2310-2313.

8. Whitehead, V. M., M. M. Perrault, and S. Stelcner. 1975. Cancer Res. 35:2985-2990.

9. Schilsky, R. L., B. D. Bailey, and B. A. Chabner. 1980. Proc. Natl. Acad. Sci. USA. 77:2919-2922.

10. Bogner, A. L., D. J. Cichowicz, and B. Shane. 1983. In Chemistry and Biology of Pteridines. J. A. Blair, editor. Walter de Gauyter and Co., New York. 627-632.

11. Cichowicz, D. J., S. K. Foo, and B. Shane. 1981. Mol. Cell. Biochem. 39:209-228.

12. McGuire, J. J., P. Hsieh, J. K. Coward, and J. R. Bertino. 1980. J. Biol. Chem. 255:5776-5788.

13. Pristupa, Z. B., P. J. Vickers, G. B. Sephton, and K. G. Scrimgeour. 1984. Can. J. Biochem. Cell Biol. 62:495-506.

14. Shane, B. 1980. J. Biol. Chem. 255:5655-5662.

15. Koizumi, S., G. A. Curt, R. L. Fine, J. D. Griffin, and B. A. Chabner. 1985. J. Clin. Invest. 75:1008-1014.

16. Rosenblatt, D. S., V. M. Whitehead, M. M. Dupont, and M. J. Vuchich. 1978. Mol. Pharmacol. 14:210-214. 
17. Witte, A., V. M. Whitehead, D. S. Rosenblatt, and M. J. Vuchich 1980. Dev. Pharmacol. Ther. 1:40-46.

18. Galivan, J. 1980. Mol. Pharmacol. 17:105-110.

19. Curt, G. A., J. Jolivet, B. D. Bailey, D. N. Carney, and B. A. Chabner. 1984. Biochem. Pharmacol. 33:1682-1685.

20. Frei, E., III, A. Rosowsky, J. E. Wright, C. A. Cucchi, J. A. Lippke, T. J. Ervin, J. Jolivet, and W. A. Haseltine. 1984. Proc. Natl. Acad. Sci. USA. 81:2873-2877.

21. Jolivet, J., R. L. Schilsky, B. D. Bailey, J. C. Drake, and B. A. Chabner. 1982. J. Clin. Invest. 70:351-360.

22. Fry, D. W., J. C. Yalowich, and I. D. Goldman. 1982. J. Biol. Chem. 257:1890-1896.

23. White, C. J., S. Lotfield, and I. D. Goldman. 1975. Mol. Pharmacol. 11:287-297.

24. Jolivet, J., and B. A. Chabner. 1983. J. Clin. Invest. 72:773-778.

25. Jacobs, S. A., R. H. Adamson, B. A. Chabner, C. J. Derr, and D. G. Johns. 1975. Biochem. Biophys. Res. Commun. 63:692-698.

26. Szeto, D. W., Y.-C. Cheng, A. Rogowsky, C.-Y., Yu, E. J. Modest,
J. R. Piper, C. Temple, R. D. Elliott, J. D. Rose, and J. A. Montgomery. 1979. Biochem. Pharmacol. 28:2633-2637.

27. Allegra, C. J., B. A. Chabner, J. C. Drake, R. Lutz, D. Rodbard, and J. Jolivet. J. Biol. Chem. In press.

28. Allegra, C. J., J. C. Drake, J. Jolivet, and B. A. Chabner. Proc. Natl. Acad. Sci. USA. In press.

29. Allegra, C. J., J. C. Drake, J. Jolivet, and B. A. Chabner. 1985. In Folyl and Antifolyl Polyglutamates. I. D. Goldman and B. A. Chabner, editors. In press.

30. Pinedo, H. M., D. S. Zaharko, J. M. Bull, and B. A. Chabner. 1976. Cancer Res. 36:4418-4424.

31. Chabner, B. A., and R. C. Young. 1973. J. Clin. Invest. 52:18041811.

32. Fry, D. W., L. A. Anderson, M. Borst, and I. D. Goldman. 1983. Cancer Res. 43:1087-1092.

33. Fabre, I., G. Fabre, and I. D. Goldman. 1984. Cancer Res. 44: 3190-3195.

34. Cowan, K. H., and J. Jolivet. 1984. J. Biol. Chem. 259:1079310800 . 